\title{
Scalable Off-Grid Energy Services Enabled by IoT: a Case Study of BBOXX SMART
}

\section{Solar}

Iwona Bisaga $^{\mathrm{a}, *}$, Nathan Holford ${ }^{\mathrm{b}}$, Ashley Grealish $^{\mathrm{c}}$, Christopher Baker-Brian $^{\mathrm{d}}$, Priti Parikh ${ }^{\mathrm{e}}$

${ }^{a}$ Civil, Environmental and Geomatic Engineering, University College London, London, United Kingdom

${ }^{\mathrm{b}}$ BBOXX, London, United Kingdom

${ }^{\mathrm{c}}$ BBOXX, London, United Kingdom

${ }^{\mathrm{d}}$ BBOXX, London, United Kingdom

${ }^{\mathrm{e}}$ Civil, Environmental and Geomatic Engineering, University College London, London, United Kingdom

*Corresponding author. Tel.: +447446185171/+250789915533

E-mail address: i.bisaga.12@ucl.ac.uk

University College London

Gower Street

WC1E 6BT

\begin{abstract}
This case study intends to show how Internet of Things (IoT) technology can be used to tackle development challenges by using the case study of BBOXX- a Solar Home Systems provider operating in South-Western Kenya and across Rwanda, and its SMART Solar platform applied to nearly 20,000 currently active systems. It aims to highlight the benefits of such technology to its users and how it can be utilised to create scalable business models for energy access through improved customer understanding. However, it also shows the difficulties in designing, developing and deploying appropriate technologies in an affordable and impactful way. Similar applications in the water sector are briefly looked at to further explore the potential and the challenges of IoT technologies in driving social and economic development. The case study raises ethical questions about the storage, collection and sharing of data and explores whether the data protection models prevalent in the developed world are applicable in a development context. It offers ideas for future research and policy recommendations, pointing to the need of including financial, socio-economic and ethical considerations in the processes of innovative solutions development.
\end{abstract}

Keywords: Solar Home Systems; remote monitoring; off-grid energy; IoT for development; energy data; offgrid energy business models 


\section{Introduction}

Approximately $85 \%$ of people who lack access to electricity live in rural areas of developing low-income countries (LICs) (World Resource Institute, 2013). Solar Home Systems (SHSs) have been prominent in addressing the challenge of alleviating energy poverty and reaching the 1.3 billion people without such access, who make up nearly half of the 2.8 billion people in the developing LICs with limited to no access to modern energy services (Hogarth and Granoff, 2015). To ensure sustainability of such systems their health should be monitored continuously for better performance and maintenance (Tejwani et al., 2014). BBOXX design, manufacture, finance and distribute SHSs in Kenya and Rwanda. To tackle challenges in their business, the company has developed SMART Solar - an innovative platform that utilises Internet of Things (IoT) technology to enable the company to scale. Combinations of distributed energy generation with IoT have recently gained recognition for their potential to lead to more efficient and cost-saving infrastructure, which may have a transformative effect on energy provision to those living off the grid (Deloitte, 2015).

Another crucial aspect of addressing a development challenge is making the solution affordable to the target market and ensuring that it is viable for the long term (Bhattacharyya, 2013; Da Silva et al., 2014). Credit is one option for increasing affordability yet financing needs to be at an acceptable level of risk to attract investors. IoT technology enables greater control over SHSs which lowers the level of risk to investors while also bringing the side-benefit of opening up options for proactive maintenance. Such technologies can piggy-back on the success of mobile network operators across the developing world by using their networks for data transfer and by taking advantage of the rapidly expanding mobile money platforms that have been innovated in the developing countries (Smertnik et al., 2014).

In Sub-Saharan Africa only, mobile market penetration has long exceeded the electrification rate (approximately $32 \%$ in 2013 , with only $13 \%$ among rural dwellers) and stood at $85 \%$ in 2014, as shown in Figure 1 . (Power for All, 2014). At the same time, mobile services have acted as an enabler for energy access among the very poor, unbanked and underbanked populations with no credit history and no other way of accessing finance (GSMA, 2015). Mobile money services are currently available in over $60 \%$ of the developing world and provide thus far financially excluded users with affordability, security and convenience which cash-based operations often lack. The number of mobile money accounts has been growing rapidly and reached 299 million at the end of 2014, with Sub-Saharan Africa being home to the highest number of registered users.

Fig. 1. Mobile market penetration and the electrification rate in Sub-Saharan Africa (Source: Power for All, 2014: 9) 
The expansion of mobile money services across the developing world has been rapid and in 2014 reached 255 live services in 89 markets, 53\% of which were in Sub-Saharan Africa (GSMA, 2015). Other mobile-enabled services currently include health, learning, agriculture, education as well as mobile insurance, credit and savings, and other services (Figure 2). Energy access, as will be demonstrated using the SMART Solar example, is affected by mobile services in three ways - as a financial gateway to unbanked customers; as a service allowing technological system innovations, including remote monitoring; and as a technology offering insight into customer data and feedback which enables more effective user-centric design practices.

Fig. 2. Mobile-enabled products and services in the developing world by sector. 'Others' includes disaster responses, energy access, green networks, mIdentity, NFC and Smart Cities. (Source: GSMA, 2015: 41)

\subsection{Literature review}

Solar energy, including SHSs, has proven to be one of the most economically feasible and easiest options to expand energy access in the developing countries (IEA, 2014). Through various financing and distribution models, SHSs have become accessible to those who have so far had to rely on other sources for energy (UNEP, 2012). SHSs offer a number of economic benefits to users, including reduction of household expenditure on inefficient lighting sources such as kerosene, wood or candles, savings on mobile phone charging and opportunities for setting up businesses or extending the time of income generating activities (Chakrabarty and Islam, 2011). Furthermore, the development of the value chain associated with solar energy services has created thousands of jobs and contributed to the formation of a new off-grid energy market, offering new funding streams flowing into the existing retail networks (Jacobson, 2007; GOGLA, 2014).

Other development impacts of SHSs include improved health due to the eradication of candle and kerosene smoke, and improved educational performance of children whose study hours extend into the evening time (SolarAid, 2015). Longer and more efficient lighting also means more time for families to socialise after dark, in a much safer, environment free of fire hazards, often accompanied by a radio or a TV, which offer access to information (Ulsrud et al., 2015; Alstone et al., 2015). Such access may be lacking in unelectrified homes or those with access limited to solar lights only. Similarly, access to smartphones is enabled. Affordable mobile phone charging, in addition to allowing for saving on charging fees, has made access to financial services possible to thus far unserved rural populations across the developing countries globally (Urmee and Harris, 2011). However, poor quality SHSs, sold upfront and without warranties have damaged the reputation of solar 
in many areas (Muok et al., 2015; Friebe et al., 2013), which has resulted in the need for the integration and a continued improvement of after-sales services offered to those adopting decentralised systems.

\subsection{Research gaps}

SHSs have been widely explored as an alternative and cost-effective option for rural electrification (Bhattacharyya, 2016; Scott and Miller, 2016; Chaurey et al., 2012; Lighting Africa, 2011; Lemaire, 2011; Jacobson, 2004). On one hand the scale-up of solar systems have been successful in Bangladesh with over 2.6 million SHS's installations covering 9\% of the electricity demand (IRENA, 2014), but on the other hand SHS programmes in Namibia, South Africa and Papua New Guinea have had limited success due to a combination of factors such as logistics, lack of training, incorrect design and installation, and lack of customer service and maintenance (Sovacool et al, 2011; Azimoh et al, 2015) There are a wide range of solar home technologies available in the market and consumers have a mixed level of satisfaction with regards to maintenance and performance of the systems (Urpelainen, 2016). There is a need for solutions which can optimise the design and performance of SHS's based on energy requirements of the end-user, enable private companies to offer improved maintenance services and improve installation and subsequent monitoring (Campana et al, 2016). Smart solar systems, which use real time data for monitoring the performance of systems, have a significant role to play in scaling up energy access as it allows for improved performance, optimisation of design of systems and improved consumer service. However, there has been a lack of research on smart Solar Home Systems (SSHSs) in contrast to the existing body of knowledge on smart grids and mini-grids for rural areas in the developing countries (e.g. Bhattacharyya and Palit, 2016; Kirchoff et al., 2016; Williams et al., 2015), as well as smart grids globally (e.g. Tuballa and Abundo, 2016; Moretti et al., 2016; Wo, Varaiya and Hui, 2015; Clastres, 2011). Considering the growing number of SHS providers who regularly monitor their systems and collect detailed usage data, it is important to better understand the benefits, risks and applications of such technologies, as well as the implications they might have for policy making in the context of distributed, innovative energy solutions.

This paper will show how IoT technology can be used to tackle development challenges by using the case study of BBOXX and its SMART Solar SHSs in Rwanda and Kenya. We examine the impact this application has on the end-users and how it can be utilised to the advantage of both the customer and the provider by offering improved customer and product understanding, and decreasing default rates among system adopters. Next, challenges associated with the development and the application of the SMART Solar platform in the context of 
an off-grid energy provider are looked at, including data costs, use and management. IoT brings with it a range of ethical challenges such as transparency, fairness, user consent, authonomy of individuals (Weber, 2013). There is a need to consider how energy consumption data collected from the SMART platform is collected, stored and used by service providers to ensure fairness and transparency to consumers, public and private sector stakeholders. One school of thought is that consumers of smart energy systems should have a right to own their data and information on their energy consumption should be used and shared only if consumers permit service providers to do so (Zhou et al, 2016). Large amounts of data will be collected, reviewed and analysed by service providers in the future, as the market for smart energy systems will grow. There is a need to consider how best to prevent risks and protect privacy whilst utilising this data (Zhou et al, 2016The case study aims to highlight the benefits of such IoT technology and how it can be used to create scalable business models. However, it also shows the difficulties in designing, developing and deploying appropriate technologies in an affordable and impactful way. It raises the ethical question of how data is collected, stored and shared and if the data protection models prevalent in the developed world are applicable in a development context.

\section{Methodology}

Literature review offers background information on the Solar Home Systems and SMART applications in the energy sector. The case study of BBOXX and its business model provides further insights into the questions surrounding innovative solutions in the off-grid energy sector, particularly in the context of developing countries.

There are three types of data that have been referred to in this case study: detailed household and collective energy usage as tracked and recorded by the SMART Solar platform and accessible on BBOXX's SMART Solar dashboard comprising of data on 20,000 active systems used by customers across Rwanda and SouthWestern Kenya; customer payment and default data which is collected on company's Enterprise Resource Planning (ERP) and Customer Relationship Management (CRM) systems (see Figure 3), for the same number of units; and finally, data cost data which has been monitored by BBOXX in the course of the last 3 years. Energy usage data for both individual households and representing collective means and averages have been anonymised for confidentiality purposes.

\section{SMART Solar}

BBOXX was founded in 2010 with a business model of wholesaling SHSs to distributors around the world. By 2013, it became clear that the model would not scale with the company's plans to provide electricity to 20 million people by 2020. Financing of the SHSs was required in order to overcome the chief barrier to adoption, 
which was the lack of upfront capital to purchase an SHS outright. The need to finance end-customers by enabling large scale institutional investment resulted in the development of SMART Solar - a product and a platform on which a traditional financial product could then be built (see Figure 3 and Figure 4). It brings together knowledge of small scale off-grid SHSs, IoT and Machine to Machine (M2M) technologies. This combination allows an operator to remotely control the products, de-activating them if customer monthly payments are missed and detecting if deliberate device tampering is attempted, which in turn reduces investors' risk. SMART Solar is also used to provide proactive servicing on all active systems. Issues such as degraded batteries or dusty solar panels can be inferred from the transmitted data. This information is communicated to the customers either through a dedicated call centre or through a network of repair technicians. Lastly, the technology is used to better understand this emerging and fast-paced market of off-grid solar energy. Data showing how customers use their lights or TVs can inform future product optimisation to better meet these needs. The ability to remotely upload new charging profiles or parameters to an SHS to ensure that a customer's battery lasts as long as possible (based on that customers usage profile) also contributes to the improvement of services.

Fig. 3. Overview of the SMART Solar architecture. Note that if the GSM network connection breaks, all data is stored in the system and sent to the server once the connection is re-established or when the system is taken for servicing.

Fig. 4. A high-level diagram illustrating the financial strategy BBOXX has adopted to scale the business.

\subsection{Impact on customer}

Initially, BBOXX found that customers who experienced technical issues were reluctant to call the service centre for help. In some cases they would prefer to withhold payments in order that contact be made with them instead. SMART Solar alerts aim to ensure that all customers receive the same quality of experience with their

SHSs. Through proactive service, the possibility of customers returning to kerosene for lighting decreases if their SHS is working well. This, in turn, builds trust in solar energy.

The combination of socio-economic benefits of using SHSs for energy generation contribute to the alleviation of poverty and its roots. SMART Solar helps to scale these impacts by making solar energy services affordable to those who cannot pay for them up front, and by improving maintenance services and customer experience through remote monitoring. However, there are also a number of challenges associated with this model of energy provision, and more specifically the SMART Solar platform. They include issues around data storage 
and sharing, as well as ways in which data collection is communicated to the users. Further benefits and challenges will be discussed in the following sections.

\subsection{Improved default rates}

One part of BBOXX's SMART Solar technology allows the automation of enabling and disabling the outputs of a SHS based on repayments made either in cash at one of BBOXX's retail stores or more commonly over a mobile money service. Such automation means a quicker response to payment delinquencies. The effect of this technology on repayment rates can be compared with BBOXX's previous model of controlling payments which involved phoning customers if payments were missed and then visiting the customer in person to remove the fuse, effectively disabling the SHS. The introduction of SMART Solar's remote control capability has brought an $82 \%$ reduction in payment default rates from $11 \%$ to just $2 \%$. Moreover, it has increased payment efficiency (avoiding late monthly payments) by $45 \%$. It is also expected to have improved customer satisfaction since reenabling an SHS typically takes less than 2 minutes with SMART Solar, whereas previously it would have taken a number of days. However, there has been no data collected which directly supports this correlation.

\subsection{Improved customer \& product understanding}

SMART Solar also helps BBOXX to better understand how customers are using its SHSs. For example, by monitoring the voltage and current of the battery, it is possible to calculate the fraction of total available energy that a customer uses each day. BBOXX is also developing algorithms that can disaggregate a series of power measurements into each device that is being used. By analysing both how much energy a customer uses, and which devices they use the energy to power, it is possible to learn about each customer's energy priorities and identify external events, as illustrated in Figures 5, 6 and 7 below. Typical energy uses among households include lighting (indoors and outdoors), mobile phone charging, and basic appliances such as radios, shavers, and TVs (desirable but not prevalent due to cost). Cooking, which poses a considerable demand for energy in households, is currently not supported by SHSs or other form of electrification (households tend to rely on firewood or charcoal, and less commonly on LPG).

Fig 5. Annotated screenshot from BBOXX's product management platform showing the net current measurements for one day. A negative current means that the battery is being charged, while a positive current means that the battery is discharging. Interesting features of the current trace have been highlighted.

Fig 6. The hourly median power consumption of entry level BBOXX households in Rwanda. Such households typically have two $1 \mathrm{~W}$ LED light bulbs and a phone charging cable. Even for bigger systems including a TV consumption remains relatively low as all appliances are energy efficient, with the TV being 15inch and 9W. 
Fig. 7. Number of flat battery events per night among BBOXX TV users in Kenya between 22nd August and 12th September 2015. Note that the spike on 6th September coincides with a spike in TV usage on the same day as Kenya played Zambia in 2017 Afcon qualifier match.

The production cost of a SHS is dominated by three components: the charge controller electronics, the PV module and the battery. Both the panel and charge controller have long expected lifetimes, however, the battery will degrade with use. Since the battery represents a large proportion of the SHS cost, and degrades quickly, it is a natural area of focus for product optimisation. BBOXX uses its remote monitoring data to inform its strategies for improving battery performance. The SMART Solar platform is used to continuously analyse the degradation of many thousands of batteries, operated under real-world conditions, thereby gaining an understanding of its battery quality that would be prohibitively expensive to achieve with lab-based tests. As well as monitoring batteries, the SMART Solar platform can be used to find optimal battery charging profiles empirically.

Controlled experiments can be conducted by subtly adjusting the charging parameters for a random sample of batteries with real users, again something that would be very difficult and expensive to replicate in a lab environment. BBOXX has extended this concept even further, allowing the optimal parameters to be tailored for each usage pattern, since not all customers use their systems in the same way. An important development has also been the ability to use other sources of data in its cloud-based platform, such as weather forecasts, to adjust SHS operating parameters based on external factors. Combining all of this together should enable BBOXX to extend the useable lifetime of sealed lead acid batteries beyond what would typically be available.

\section{Scalable financing model}

Understanding its customers' behaviour and improving repayment rates has enabled BBOXX to scale up its financing of customers, a challenge which is often a barrier to growth in the off-grid electrification market (Bhattacharyya, 2013). The increased payment rates and customer understanding have been utilised to create Asset-Backed Securities (ABS), a financial product that sells the future receivables from customers pay plan contracts to investors who recover their investment plus interest over time as customers make their monthly repayments. Creating ABSs reduces the time for BBOXX to recover the costs of financing an end customer which greatly improves the cash flow within the business and allows it to scale up the number of customers and deployed units at a much more aggressive rate. One of the important factors when selecting a pool of customer contracts to create an ABS is ensuring that the expected delinquency and default rate is low. To do this, BBOXX leverages both its payments history data and its customer behaviour data from the SMART Solar platform to accurately group together customers into an ABS pool. 


\section{Challenges}

Developing in-house IoT solutions such as SMART Solar, which allow providers to offer their own customer credit, can be a costly and lengthy process. For many small and medium scale solar energy companies developing such solutions might not be viable and thus may set them back in pursuing market growth by losing the competitive advantage of other providers (Nique and Smertnik, 2014). This, in turn, means that scaling to reach greater numbers of unelectrified communities may be hindered. Developing tools and solutions which can be applied to SHS providers regardless of their business models and in-house technical capacity could be one way. There have been advancements in business solutions which aim to address that gap and allow SHS providers to apply their mobile money and remote system control solutions directly, without the need to develop often complex IoT technologies in-house (Scott and Miller, 2016; Pueyo, 2013). An additional burden which may arise is the cost of data and services from local network providers, which are necessary for a proper functioning of such technologies. Equally important is the reliability of networks for remote monitoring and mobile payment applications. Systems which are heavily dependent on the communication uptime for service delivery can face considerable challenges due to lack of reliability and latency of GSM networks, which can in turn impede further growth and scalability of such solutions (Nique and Arab, 2013).

\subsection{Data cost}

Fig. 8. Monthly cost of GSM data services for BBOXX's SHSs with scale.

BBOXX use embedded international roaming SIM cards in order to simplify its supply chain and centralise billing. However, such SIM cards are offered on plans that are relatively expensive in terms of $\$$ per megabyte, especially at low volumes. Through a combination of volume discounts, reduction of data use (through better data compression and technologies) and better negotiation by having multiple competing suppliers, BBOXX has reduced the cost per unit per month to roughly $1 / 9$ of the original cost (Figure 6).

As well as the high cost of data at small volumes, new entrants also face difficulties in integrating SIM management with their existing software. All SIM suppliers provide a dashboard for managing SIMs with actions such as activation and monitoring of data usage. However, even for 1,000 SIMs the dashboard can become cumbersome to use. Therefore, it is necessary to automate common actions through a supplier's Application Program Interface (API), which takes engineering effort which in turn can represent a large upfront cost. 
There is also a high cost associated with the hardware (see Table 1 for breakdown). The total cost of a modem, antenna and SIM card was initially around \$20 for BBOXX. This is a large proportion of the total production cost of an SHS. Other costs and their proportions of the total system making cost are presented in Table 2.

\section{Table 1}

GSM-based technology development costs.

Table 2

Components of making and monitoring the system and their percentage of the total system cost.

The extra costs associated with the SMART Solar SHS make for another challenge, namely keeping the price of the system at a level which will be affordable to the customer. World Resource Institute $(2013,5)$ have described the core innovative business strategies of socially oriented energy enterprises and organisations as the following: understanding consumer preferences, needs and the ability to pay; demonstrating the value of a new energy service delivery model or a new technology; building strong consumer trust in the product and the entire supply chain, and maintaining that trust; designing and implementing financing and payment schemes suitable for the customers' budgets.

These strategies very well reflect the key areas which energy providers to low-income users have to carefully consider and reconcile. Creating an innovative solution and at the same time making it accessible, affordable, trustworthy and matching the needs of the target users is a set of complex challenges facing BBOXX and other SHS providers.

\subsection{Data use}

Datasets such as that of BBOXX may be of value for researchers and practitioners who are interested in the profiles and habits of SHS customers. Allowing access to data for research purposes opens up opportunities to better understand the customer base, from a variety of perspectives: technical, social, economic and more. Results of data analysis can be used to maximise benefits for both the customers and the providers, although data handling and sharing requires particular caution given its often sensitive nature (WEF, 2012). Patterns of daily energy use can provide a high-resolution picture of customers' daily habits and practices- a data set which, if mishandled, could negatively affect the customers by invading their personal domain. It is important that businesses and other organisations familiarise themselves with local regulatory frameworks (if such are in place) around data privacy, security and management in order to avoid any infringement (ibid.).

Another challenge associated with the SMART Solar platform concerns helping the customer to understand what data is being collected and how, and the ethical implications of such data collection processes. Explaining the concept of data, its value and meaning is thought to be difficult among the demographic targeted by BBOXX 
and similar providers (May and Diga, 2015). There are currently several other SHS providers using remote monitoring for improved services and customer understanding (e.g. M-Kopa, Azuri Technologies, Simpa Networks), however, there is a lack of data on what the customers' perception and reception of such a technology is. Similarly, there appears to be little to no user feedback regarding the concept of data itself. Therefore, it proves difficult to predict customers' acceptance rate of collecting, processing and using their data collected by their SHS for a variety of business purposes.

\section{Future research}

More work needs to be done within the domain of smart energy solutions for off-grid systemsto understand issues around data and privacy and, if necessary, to improve communication to customers on these subjects. The challenges associated with data handling, briefly mentioned here, highlight the need for developing appropriate data management infrastructures, and recognising the importance of data security and privacy while working with IoT, particularly given the local context which may differ from the accepted norms of the Global North (Weber, 2010). Ensuring data is used for increasing positive social impact is also critical. Given the amount of high resolution data collected from the SHSs daily, it is possible to learn a lot about the energy use patterns in households which is the kind of information that could drive the electrification strategy for areas where off-grid solutions make the most sense, such as remote, geographically challenging locations which might not be reached by the grid network in the near future. The data collected through smart solar home systems has a role to play in improving the design and maintenance of systems. However, data misappropriation and misuse, given its sensitive nature, could be used to negative effects, breaching users' privacy.

\subsection{Application of learnings and smart systems}

6.2. An effective application of learnings from data and from customer feedback is key to improving products and services. There has been a growing recognition of user-centric design methodologies in achieving greater impact in addressing most pressing development challenges (GSMA, 2013). Today, service providers who have access to a vast amount of information allowing them to tailor products and services in ways which would have been impossible before are under pressure to lead social innovation and change. Other examples of such technologies in Sub-Saharan Africa and India are briefly discussed below in order to further demonstrate their potential and wide-reaching scope. User-centric design with a combination of cross-disciplinary approaches, including engineering and social sciences, has the potential to best address the challenges and utilise the benefits of IoT technologies, in particular across the developing world where they are often most desperately needed. Understanding consumer demand and consumption of energy is 
crucial for optimising the design, installation and performance of off-grid systems. A transition to smart energy systems is the most effective way to meet the increasing energy demand globally as smart systems enable service providers to provide efficient, reliable, environmentally friendly and commercially viable services (Dincer, 2016). Within the domain of smart energy systems, there is a paucity of research on smart solar home systems as compared to smart grid systems. Further research on smart systems for off-grid solutions will support scale-up of energy access in remote rural communities (Bhattacharyya \& Palit, 2016).

\section{Other applications}

There are a number of remotely monitored technologies already deployed outside the energy sector, e.g. in water provision. Water kiosks with embedded smart sensors have been introduced across Sub-Saharan Africa by providers such as Grundfos Lifelink in Kenya and Uganda, and Safe Water Network in Kenya and Ghana (Nique and Opala, 2014). By leveraging IoT technologies, they improve operations and optimise services by equipping kiosks with a number of sensors coupled to a GSM meter transmitting real-time data about customer payments and the availability of water on each site (ibid.). A similar application has been used by Sarvajal, a franchise-based off-the-grid water purification and provision business in India. Sarvajal have applied a two-way monitoring device sending real-time information on levels of water production and information allowing the operators to track any technical service issues (Macomber and Sinha, 2012).

Nearly all challenges that have been outlined for SMART Solar are present in the case of similar technologies in the water sector. Making solutions affordable and accessible while meeting the individual needs is of equal importance. Network reliability and data handling also have to be considered, although the ethical questions around the nature of data may not be as problematic given that data is collected for equipment outside of the household environment and may be seen as less sensitive than in the case of SHSs. In the instance of smart sensors to monitor water kiosks, the solutions have been developed in-house, similarly to SMART Solar. Approaches that rely on cost recovery, it has been argued, are more efficient and keep the water service prices for users at an affordable level when deployed in dense communities (peri-urban and urban rather than rural) (Safe Water Network, 2013).

\section{Conclusions and policy recommendations}

This case study has shown how the application of SMART Solar technology has enabled the improvement of energy services to thousands of users of SHSs. Similar technologies have been applied among other energy providers, as well as various other services, including remotely monitored water kiosks (e.g. Sarvajal in India). However, there are still gaps in detailed understanding of the impacts these technologies are making on 
customers, and the actual awareness of the principles on which such technologies are built among those who use them or are affected by them. What is more, the potential for utilising data collected through smart systems for impact assessment, particularly in the energy sector, is yet to be fully realised especially in the domain of offgrid systems. There is a need to consolidate and develop a strong evidence base on the impact of SMART solar home systems for enhancing consumer satisfaction, improving cost effectiveness, performance and improving resource use thereby leading to sustainability. In order to meet the gap in rural electrification the market for offgrid energy services need to be strengthened through improved market intelligence on consumer demand thereby leading to cost effective services. Future policy considerations include a stronger focus on smart offgrid solutions as compared to smart grids and the need for a well-defined regulatory framework for monitoring and evaluating performance of off-grid systems.

Future research and policy considerations could also focus on data use, privacy and management, and on gaining better insights into the customers' perceptions of remote monitoring applications. As proposed by Clastres (2011) in relation to smart grids, a regulation system which would define the beneficiaries and ensure customer protection rights is necessary in order to prevent possible data misuse. The fact that data is collected by private providers calls for a more inclusive collaboration and partnership of both public and private stakeholders, and joint efforts in developing systems and regulations around the growing number of data sets. End-user participation would offer insights into the current understanding of such technologies and guidance on how to communicate to them the nature of the information being collected, as well as the benefits and potential risks. This kind of end-user involvement would also allow to help eliminate any misconceptions about smart solutions among the users, something that has been challenging in BBOXX's experience to date. Efforts to spread awareness of and promote off-grid solutions, including SHSs, have been undertaken by various stakeholders in a form of marketing activities and campaigns, such as the recent Rural Electrification campaign lead by the Government of Rwanda. Included in such strategies are components focusing on improving the understanding of the off-grid technology itself. Building basic awareness of smart solutions and remote monitoring of systems could be an additional component included in these efforts.

More work is required to investigate the feasibility of further extending similar IoT technologies to other services satisfying basic needs of communities around the world without access to energy, water, sanitation or shelter. Consideration should also be given to ways in which existing innovative solutions could be scaled up to reach greater numbers of people more quickly and effectively, with financial, socio-economic and ethical factors 
all considered in the process. Knowledge and best practice sharing should be encouraged among providers of smart solutions across sectors and countries.

\section{Acknowledgements}

The authors would like to thank BBOXX and its entire team in London, Rwanda and Kenya, for the support provided in the course of writing this paper and for making this piece of research possible. Special thank you goes to the users of SMART Solar Home Systems who are the promoters of innovation and modern energy access in places where living off-grid is still prevalent. 


\section{References}

Alstone, P., Gershenson, D., \& Kammen, D.M. (2015). Decentralized energy systems for clean electricity access. Nature Climate Change, 4(5), 305-314.

Azimoh CL, Klintenberg P, Wallin F, Karlsson B. Illuminated but not electrified: an assessment of the impact of Solar. Applied Energy 2015;155:354-64

Bhattacharyya, S. (2011). Special issue on Off-grid electrification in developing countries. Energy for Sustainable Development, 15(3), 201-202.

Bhattacharyya, S.C. (2013). Financing energy access and off-grid electrification: A review of status, options and challenges. Renewable and Sustainable Energy Reviews, 20(2013), 462-472.

Bhattacharyya, S.C. \& Palit, D. (2016). Mini-grid based off-grid electrification to enhance electricity access in developing countries: What policies may be required? Energy Policy, 94(2016), 166-178.

Campana, P. E., Holmberg, A., Pettersson, O., Klintenberg, P., Hangula, A., Araoz, F. B., ... \& Yan, J. (2016). An open-source optimization tool for solar home systems: A case study in Namibia. Energy Conversion and Management, 130, 106-118.

Chaakrabarty, S. \& Islam, T. (2011). Financial viability and eco-efficiency of the solar home systems (SHS) in Bangladesh. Energy, 36(2011), 4821-4827.

Chaurey, A., Krithika, P. R., Palit, D., Rakesh, S., \& Sovacool, B. K. (2012). New partnerships and business models for facilitating Energy access. Energy Policy, 47(2012), 48-55.

Clastres, C. (2011). Smart grids: Another step towards competition, Energy security and climate change objectives. Energy Policy, 39(9), 5399-5408.

Da Silva, I., Batte, G., Ondraczek, J., Ronoh, G., \& Ouma, C.A. (2014). Diffusion of Solar Energy Technologies in Rural Africa: Trends in Kenya and the Luav Experience in Uganda. In $1^{\text {st }}$ Africa Photovoltaic Energy Conference and Exhibition, Durban, South Africa.

Deloitte (2015). Sub-Saharan Africa Power Trends. Power Disruption in Africa. Report.

Dincer, I. \& Acar, C. (2016) Smart energy systems for s sustainable future, Applied Energy, 194 (2017). 225235 
Friebe, C.A., von Flotow, P., \& Taube, F.A. (2013). Exploring the link between products and services in lowincome markets- Evidence from solar home systems. Energy Policy, 52(2013), 760-769.

Global Off-Grid Lighting Association (GOGLA) (2014). Investment and Finance Study for Off-Grid Lighting. Resource document. http://global-off-grid-lighting-association.org/wp-content/uploads/2013/09/A-T-KearneyGOGLA.pdf. Accessed 6 November 2015.

GSMA (2013). Scaling Mobile for Development. https://gsmaintelligence.com/research/?file=130828-scalingmobile.pdf\&download Accessed 21 January 2016.

GSMA (2015). The Mobile Economy. Resource document. GSMA.

http://www.gsmamobileeconomy.com/GSMA_Global_Mobile_Economy_Report_2015.pdf Accessed 21 January 2016.

Hogarth, J.R. \& Granoff, I. (2015). Speaking truth to power : why energy distribution, more than generation, is Africa's poverty reduction challenge. In Working and disscussion papers, Overseas Development Institute, May 2015.

International Energy Agency (2014). World Energy Outlook 2014. Resource document. International Energy Agency. http://www.worldenergyoutlook.org/weo2014/. Accessed 6 November 2011.

International Renewable Energy Agency (IRENA). Accelerating off-grid renewable energy - IOREC 2014: key findings and recommendations, http://www.irena.org/DocumentDownloads/Publications/IRENA_2nd_IOREC 2015.pdf; 2015 [accessed 18.04.17].

Jacobson, A. (2007). Connective Power: Solar Electrification and Social Change in Kenya. World Development, 35(1), 144-162.

Kirchoff, H., Kebir, N., Neumann, K., Heller, P.W., \& Strunz, K. (2016). Developing mutual success factors and their application to swarm electrification: microgrids with $100 \%$ renewable energies in the Global South and Germany. Journal of Cleaner Production, 128(2016), 190-200.

Lemaire. X. (2011). Off-grid electrification with solar home systems: The experience of a fee-for-service concession in South Africa. Energy for Sustainable Development, 15(3), 277-283. 
Lighting Africa (2011). The Off-Grid Lighting Market in Sub-Saharan Africa: Market Research Synthesis Report. Resource document. Lighting Africa (IFC \& WB). http://global-off-grid-lighting-association.org/wpcontent/uploads/2013/09/LA-Mkt-Synthesis.pdf. Accessed 3 October 2016.

Macomber, J.D., \& Sinha, M. Sarvajal: Water for All. Harvard Business School Case 211-028, February 2011. (Revised September 2013).

May, J.D. \& Diga, K. (2015). Progress Towards Resolving the Measurement Link Between ICT and Poverty Reduction. In A. Chib, J.D. May, \& R. Barrantes (Eds.), Impact of Information Society Research in the Global South (pp. 83-104). New York : Springer.

Moretti, M., Njakou Djomo, S., Azadi, H., May, K., De Vos, K., Van Passel, S., \& Witters, N. (2016). A systematic review of environmental and economic impacts of smart grids. Renewable and Sustainable Energy Reviews.

Muok, B. O., Makokha, W., \& Palit, D. (2015). Solar PV for Enhancing Electricity Access in Kenya: What Policies are Required? Resource document. The Energy and Resources Institute. http://www.teriin.org/policybrief/files/SolarPV/files/basic-html/page1.html. Accessed 6 November 2015. Nique, M. \& Arab, F. (2013). Sustainable Energy \& Water Access through M2M Connectivity. Resource document GSMA. http://www.gsma.com/mobilefordevelopment/wp-content/uploads/2013/01/SustainableEnergy-and-Water-Access-through-M2M-Connectivity.pdf Accessed 21 January 2016.

Nique, M \& Opala, K. (2014). The Synergies Between Mobile, Energy and Water Access : Africa. Resource document. GSMA Mobile Enabled Community Services. http://www.gsma.com/mobilefordevelopment/wpcontent/uploads/2014/04/MECS_Synergies-between-Mobile-Energy-and-Water-Access_Africa.pdf. Accessed 6 November 2015 .

Nique, M. \& Smertnik, H. (2014). The Synergies between Mobile Phone Access and Off Grid Energy Solutions. In Schafer, M. et al. (eds.) Innovating Energy Access for Remote Areas: Discovering Untapped Resources. Proceedings of the International Conference University of California, Berkeley.

Power for All (2014). The Energy Access Imperative. Resource document. Practical Action. http://policy.practicalaction.org/resources/publications/item/power-for-all-the-energy-access-imperative Accessed 21 January 2016. 
Pueyo, A. (2013). Real Time Monitoring Technologies for Pro-Poor Access to Electricity. IDS Evidence Report, 12.

Safe Water Network (2013). Ghana Market Assessment: Market-Based Provision of Water at the Community Level. Resource document. Safe Water Network. http://www.safewaternetwork.org/sites/default/files/Ghana_Market_Review-2013.pdf Accessed 21 January $\underline{2016 .}$

Scott, A. \& Miller, C. (2016). Accelerating access to electricity in Africa with off-grid solar. The market for solar household solutions. Report. Resource document. ODI. http://www.sun-connectnews.org/fileadmin/DATEIEN/Dateien/New/Market_for_SHS.pdf. Accessed 7 October 2016.

Smertnik, H., Kassam, A., Roach, M., Nique, M., Cohen, I., \& Shah, R. (2014). Predicting the Future of MobileEnabled Community Services. Resource document. GSMA Mobile Enabled Community Services. http://www.gsma.com/mobilefordevelopment/wp-content/uploads/2014/05/GSMA_MECS_Annual-Report2013.pdf. Accessed 1 November 2015.

SolarAid (2015). Impact Report Autumn 2015. Resource document. SolarAid http://www.solaraid.org/assets/Uploads/Impact-week-2015/SolarAid-IMPACT-REPORT-2015.pdf. Accessed 1 November 2015. Tejwani, R., Kumar, G., \& Solanki, C. (2014).Remote Monitoring for Solar Photovoltaic Systems in Rural Application using GSM Voice Channel. Energy Procedia, 57(2014), 1526-1535.

Tuballa, M.L. \& Abundo, M.L. (2016). A review of the development of Smart Grid technologies. Renewable and Sustainable Energy Reviews, 59(2016), 710-725.

Ulsrud, K., Winther, T., Palit, D., \& Rohracher, H. (2015). Village-level solar power in Africa: Accelerating access to electricity services through a socio-technical design in Kenya. Energy \& Social Science, 5(2015), 3444.

United Nations Environment Programme (UNEP) (2012). Financing renewable energy in developing countries. Drivers and barriers for private finance in Sub-Saharan Africa. Resource document. UNEP Finance Inititative http://www.unepfi.org/fileadmin/documents/Financing_Renewable_Energy_in_subSaharan_Africa.pdf. Accessed 3 November 2015. 
Urmee, T. \& Harries, D. (2011). Determinants of the success and sustainability of Bangladesh's SHS program. Renewable Energy, 36(2011), 2822-2830.

Urpelainen, J. (2016) Energy poverty and perceptions of solar power in marginalized communities: Survey evidence from Uttar Pradesh, India, Renewable Energy, 85 (2016), 534-539

Weber, R. (2010). Internet of Things - New security and privacy challenges. Computer Law \& Security Review, 26(2010), 23-30.

Williams, N.J., Jaramillo, P., Taneja, J., \& Ustun, T.S. (2015). Enabling private sector investment in microgridbased rural electrification in developing countries: A review. Renewable and Sustainable Energy Reviews, 52(2016), 1268-1281.

World Economic Forum (WEF) (2012). Big Data, Big Impact: New Possibilities for International Development. Resource document. World Economic Forum http://www3.weforum.org/docs/WEF_TC_MFS_BigDataBigImpact_Briefing_2012.pdf. Accessed 6 November 2015.

World Resource Institute (WRI) (2013). Implementation Strategies for Renewable Energy Services in LowIncome Rural Areas. Resource document. World Resource Institute.

http://www.wri.org/sites/default/files/pdf/implementation_strategies_renewable_energy_services_low_income_r ural_areas.pdf Accessed 21 January 2016.

Wu, F.F., Varaiya, P.P., \& Hui, R.S.Y. (2015). Smart Grids with Intelligent Periphery: An Architecture for the Energy Internet. Engineering, 1(4), 436-446.

Zhou, K., Fu, C., \& Yang, S. (2016). Big data driven smart energy management: From big data to big insights. Renewable and Sustainable Energy Reviews, 56, 215-225. 